\title{
DEVELOPMENT OF A NEW CAST AND WROUGHT ALLOY (RENÉ 65) FOR HIGH TEMPERATURE DISK APPLICATIONS
}

\author{
Joseph A. Heaney ${ }^{1}$, Michael L. Lasonde ${ }^{1}$, Andrew M. Powell ${ }^{1}$, Betsy J. Bond ${ }^{2}$, Christopher M. \\ O'Brien $^{2}$ \\ ${ }^{1}$ General Electric Aircraft Engines, \\ One Neumann Way, Cincinnati, Ohio, 45215, USA \\ ${ }^{2}$ ATI Specialty Materials \\ 2020 Ashcraft Avenue, Monroe, NC, 28110, USA
}

Keywords: René 65, Superalloys, Cast and Wrought, Turbine Disks, Microstructure, Gamma Prime, Mechanical Properties

\begin{abstract}
René 65 was developed as a nickel-base, gamma prime strengthened, aerospace turbine disk superalloy to provide increased temperature capability compared to direct age (DA) 718 and bridge the performance and cost gap between traditional cast and wrought alloys and powder alloys. A full scale development program was successfully executed to define a robust processing window resulting in successful production introduction of the alloy. Conventional hot die forging, over a wide range of strain rate processes, has been demonstrated as well as successful ring rolling. Optimized heat treatment processing has resulted in approximately $90^{\circ} \mathrm{C}$ temperature capability increase over DA718 with excellent fatigue and damage tolerance capability. This paper presents results for alloy development, forge processing, heat treatment, microstructure characterization and mechanical property assessment.
\end{abstract}

\section{Introduction}

Over the years, cast and wrought materials such as Alloy 718 have found widespread use in gas turbine rotating components. Unfortunately, the temperature limitation of this alloy, as cited in the literature, is approximately $649^{\circ} \mathrm{C}$ [1]. While GE's use of Alloy 718 today in these applications has remained strong, the need for advanced superalloy disk materials for new engine platforms is growing rapidly. Figure 1 illustrates the predicted change in Alloy 718 and advanced superalloy materials for GE engines over the next decade. By the year 2024, the utilization of advanced superalloys in both cast and wrought and powder forms for critical gas turbine rotating components is predicted to be comparable to that of Alloy 718 . 


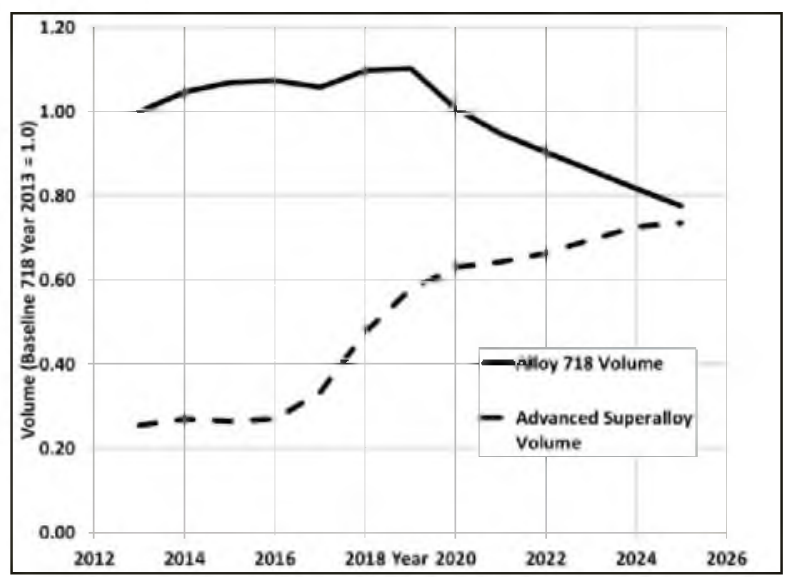

Figure 1. Predicted Change in GE Advanced Superalloy Material Utilization.

Higher operating temperatures required for increased gas turbine engine performance have led to increased use of powder alloys such as René 88DT (R88DT) and René 104 (R104) for the manufacture of critical rotating aircraft engine components. These materials are especially effective in high pressure turbine applications, but have also been utilized in the latter stages of selected compressors. While providing the required strength, creep, fatigue, and dwell time fatigue crack growth capability at elevated temperatures, their application comes with a cost penalty due to the expensive powder processing route required.

Industry efforts have continued to develop cast and wrought alloys to bridge the gap between Alloy 718 and powder alloys. This has resulted in the development of such alloys as ATI 718Plus ${ }^{\mathrm{TM}}$, Alloy 720 , and $\mathrm{AD} 730^{\mathrm{TM}}$ for high temperature disk applications [2]. GE's approach to fill this need was to start with a successful powder alloy, R88DT, and adapt its chemistry and processing to facilitate cast and wrought manufacture. In 2007, GE entered into a Joint Technology Development Agreement with ATI Specialty Materials to develop this approach for R88DT. The resulting cast and wrought alloy, now designated as René 65 , is currently in full production across multiple GE engine lines. The objective of this paper is to review its development.

\section{Composition}

René 65 is a derivative of the powder metal alloy R88DT with chemistry modifications to enable cast and wrought processing. Phase stability modeling (Thermo-Calc ${ }^{\mathrm{TM}}$ ) was utilized to target an iron content to enhance the ability to recycle machine turnings. Results showed that the largest impact of increasing the iron content is an increased sigma solvus temperature. Sigma phase is a well-known topologically close-packed (TCP) phase that can reduce mechanical property capability. At $2 \%$ iron, the sigma solvus temperature is coincident with the aging temperature of the alloy and a maximum value of $1.3 \%$ was selected and demonstrated to provide sufficient margin to avoid sigma formation. Experimentally, long-term exposure tests at $760^{\circ} \mathrm{C}$ up to 10,000 hours confirmed the lack of sigma formation.

Subscale studies were conducted to establish the relationship between interstitial levels and resulting product microcleanliness. Figure 2 illustrates the increase in nitride stringer frequency with increasing nitrogen content. Elevated levels of nitrogen and carbon were found to adversely affect low cycle fatigue capability as shown in Figure 3. The $Z$ values reflect the number of 
standard deviations from expected average behavior with the non-LI (low interstitial) tests approximately $0.8 \mathrm{Z}$ lower in fatigue capability compared to LI tests.

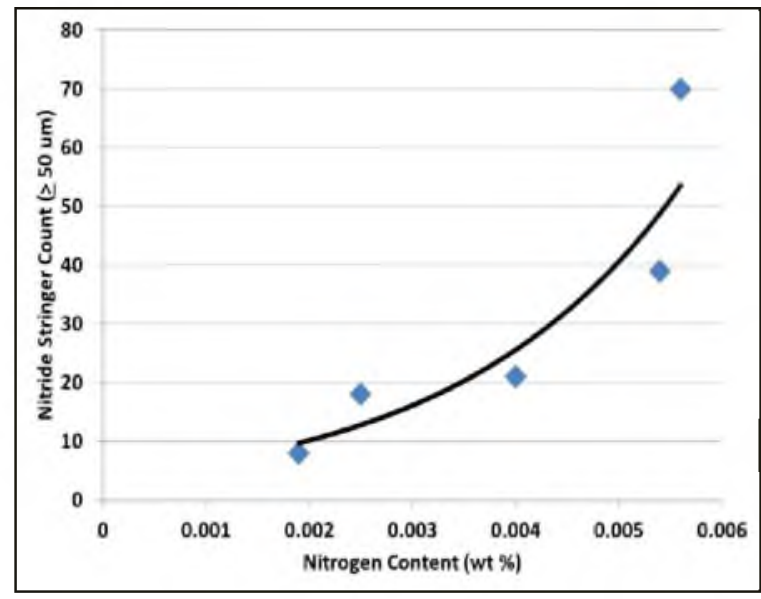

Figure 2. Effect of Nitrogen on Nitride Stringers Frequency.
Normal Probability Plot for Z-Score By Interstitial

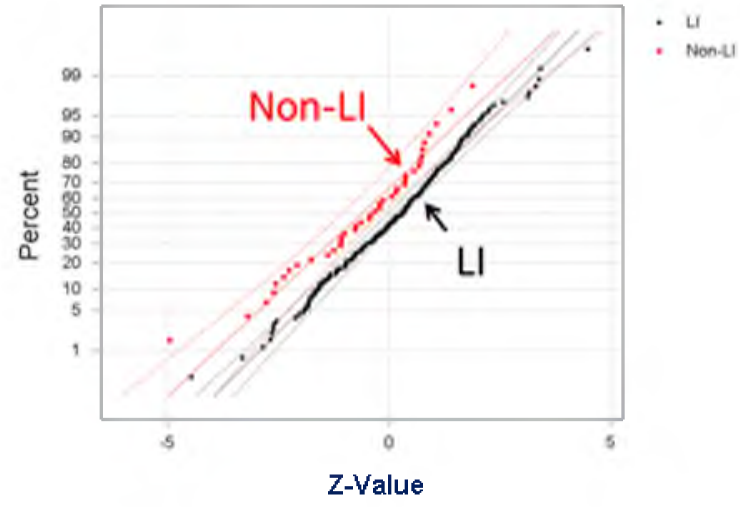

Figure 3. Effect of Interstitial Level on Fatigue Capability.

As a result, a low interstitial version was developed for improved microcleanliness and low cycle fatigue. The carbon level for low interstitial cast and wrought alloys, such as Alloy 720 and $\mathrm{AD} 730^{\mathrm{TM}}$, is typically shown as 0.015 weight percent [2]. The final René 65 nominal composition selected is shown in Table I compared to other high temperature cast and wrought disk alloys.

Table I. Nominal Alloy Composition Comparison (Weight Percent)

\begin{tabular}{|l|c|c|c|c|c|c|c|c|c|c|c|}
\hline & $\mathbf{N i}$ & $\mathbf{C r}$ & $\mathbf{M o}$ & $\mathbf{W}$ & $\mathbf{C o}$ & $\mathbf{F e}$ & $\mathbf{N b}$ & $\mathbf{T i}$ & Al & Zr & B \\
\hline Alloy 718 & Bal. & 18.1 & 2.9 & - & - & 18 & 5.4 & 1 & 0.45 & - & - \\
\hline ATI 718 Plus $^{\mathrm{TM}}$ & Bal. & 18 & 2.8 & 1 & 9 & 10 & 5.4 & 0.7 & 1.45 & - & 0.006 \\
\hline Alloy 720 & Bal. & 16 & 3 & 1.25 & 15 & - & - & 5 & 2.5 & 0.03 & 0.015 \\
\hline Waspaloy & Bal. & 19.4 & 4.25 & - & 13.25 & - & - & 3 & 1.3 & 0.05 & 0.006 \\
\hline René 65 & Bal. & 16 & 4 & 4 & 13 & 1 & 0.7 & 3.7 & 2.1 & 0.05 & 0.016 \\
\hline
\end{tabular}

\section{Ingot and Billet Processing}

To provide for optimum chemistry, microcleanliness, and solidification control, a triple melt (VIM, ESR, VAR) melting process was selected. The intermediate ESR step not only results in improved microcleanliness but provides a solid electrode for optimum VAR process stability. Development was conducted on full scale VIM heats, ESR ingots and VAR ingots (508 $\mathrm{mm}$ ) using a Design of Experiments (DOE) approach to optimize process parameters. Melting and remelting practices were originally tailored after production procedures utilized for Alloys 718 and 720 , then slightly modified based on the DOE results to provide a robust process window. To date, hundreds of VAR ingots have been successfully produced and converted to billet.

Conversion to billet is accomplished using an upset and draw practice with initial breakdown on a hydraulic press followed by radial forging. To date, billet diameters of $254 \mathrm{~mm}$ and smaller have been successfully produced and trials are currently underway to develop larger size capability. Billet matrix grain sizes typically range from ASTM $8-11$. The fine microstructure and gamma prime distribution allows ultrasonic testing to the same standards as fine grain Alloy 
718 billet. Detailed René 65 billet characterization studies have been described by Bond et al [3].

\section{Forging}

René 65 has been developed for use primarily in the turbine section of engines. The workability of René 65 has been found to be good when forging in the temperature range of $1038^{\circ} \mathrm{C}$ to $1079^{\circ} \mathrm{C}$. Demonstration and evaluation of René 65 forging properties has been through the manufacture of over forty different full scale turbine engine components including high pressure turbine disks and seals with forging weights up to approximately $225 \mathrm{~kg}$. Forging processes including isothermal, conventional closed die and ring rolling have been evaluated and have successfully been used to manufacture forgings of René 65. Representative parts manufactured by both closed die and ring roll forge processing are shown in Figure 4.

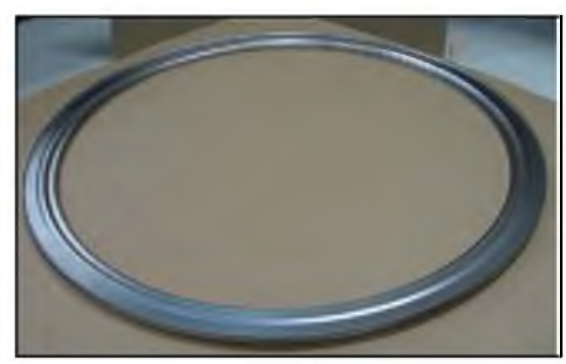

(a)

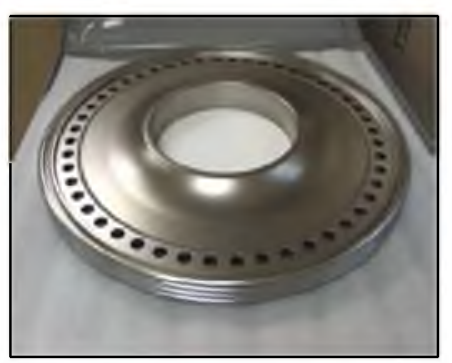

(b)

Figure 4. Representative René 65 Parts Manufactured by: a) Ring Rolling and b) Closed Die Forging.

Structure control during forging has been demonstrated throughout a range of forge processes from low strain rate processes such as isothermal forging to high strain rate processes where rates are greater than $10 / \mathrm{sec}$. Modeling of the forge process has been extensively used in development of forging practices to achieve and maintain the fine grain sub-solvus microstructure of René 65. Flow stress over a range of temperature, strain, and strain rate conditions along with physical property data has been generated and utilized in the modeling of the forging of René 65.

\section{Heat Treatment}

René 65 is a solution and age alloy that derives its strength and creep capability from gamma prime formation. The quench from solution is the key processing step to establish acceptable properties. Depending on the shape, thickness and future machinability concerns, a range of different quench media and delay times can be selected to meet the material requirements Nominal heat treatment consists of a $1066^{\circ} \mathrm{C}$ solution followed by a $760^{\circ} \mathrm{C}$ single age. Thermal modeling may be utilized for selecting the optimum solutioning cycle to provide a sufficient cooling rate to achieve the desired mechanical properties while minimizing residual stress for improved machinability. To date, René 65 forgings have been successfully quenched with oil, polymer, fan and salt. 
In general for Rene 65 , the faster the average cooling rate through the gamma prime precipitation range, the higher the tensile strength capability and the higher the creep capability, but at the cost of higher residual stresses and possible part movement during the final machining process. Figure 5 illustrates the effect of cooling rate on ultimate tensile strength and yield strength at $400^{\circ} \mathrm{C}$ and $649^{\circ} \mathrm{C}$. As seen, yield strength is more sensitive to cooling rate than ultimate tensile strength. The increased strength capability with increased cooling rate does not continue indefinitely. At cooling rates above $149^{\circ} \mathrm{C} / \mathrm{min}$, the strength properties level off.
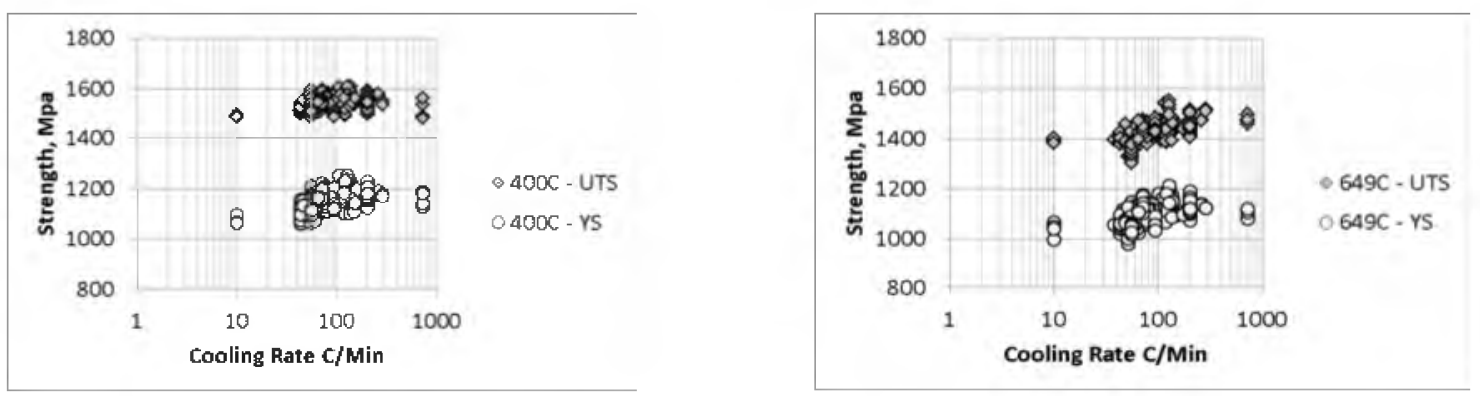

Figure 5. Effect of Cooling Rate on $0.2 \%$ Yield and Ultimate Tensile Strength of René 65.

The effect of cooling rate on $1 \%$ creep is also stress dependent with higher stresses exhibiting a greater effect as illustrated in Figure 6 for material tested at $704^{\circ} \mathrm{C}$.
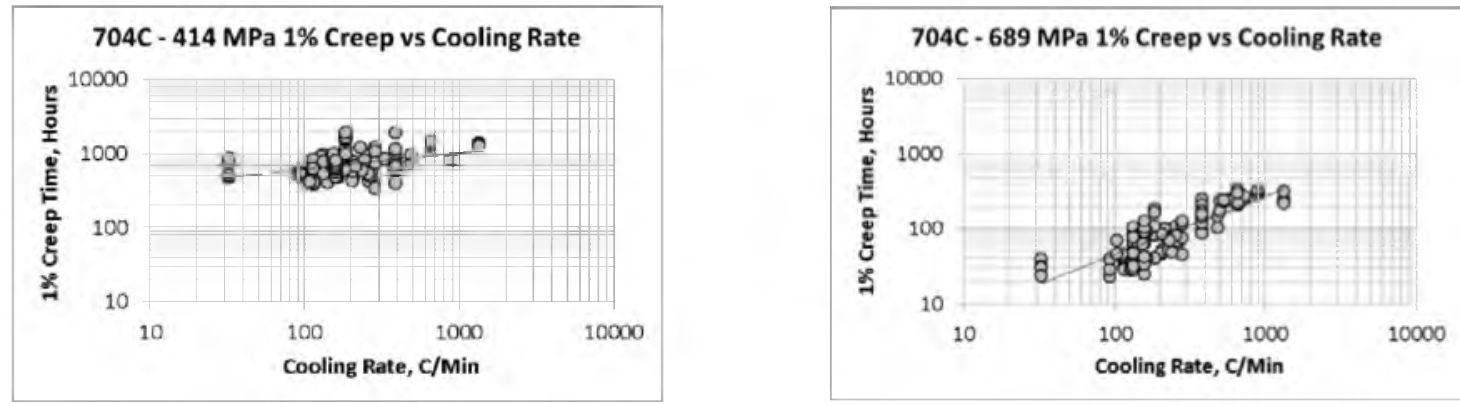

Figure 6. Stress Dependency of Cooling Rate on Creep Properties.

The underlying mechanism for both the high stress creep response and the tensile strength response is the modification of the gamma prime distribution. As the average cooling rate decreases, the secondary gamma prime size increases from its desired starting size below 100 $\mathrm{nm}$. Figure 7 contains $10,000 \mathrm{X}$ scanning electron microscope (SEM) images showing the extremes of the secondary gamma prime size at $149^{\circ} \mathrm{C} / \mathrm{min}$ (a) vs $10^{\circ} \mathrm{C} / \mathrm{min}$ (b).
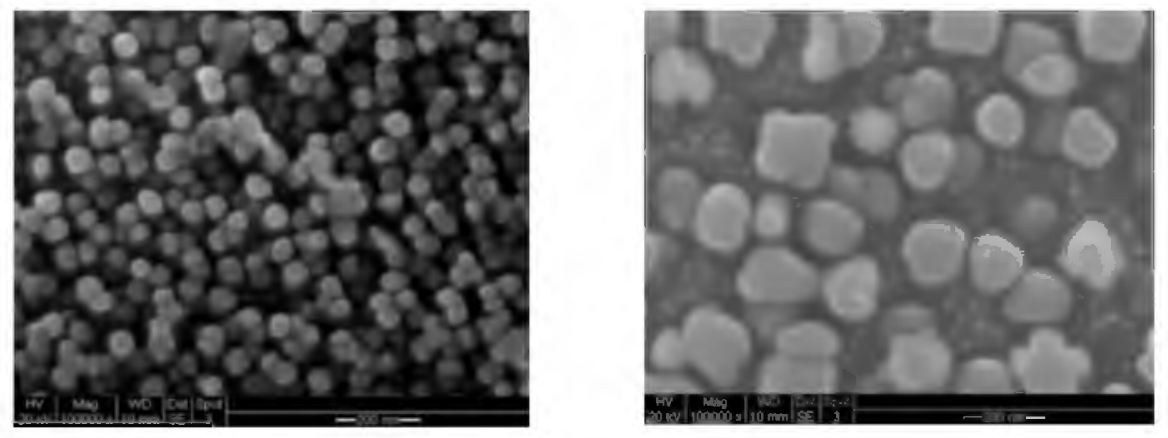

a. Avg. Cooling Rate $149^{\circ} \mathrm{C} / \mathrm{min}$.
b. Avg. Cooling Rate $10^{\circ} \mathrm{C} / \mathrm{min}$.

Figure 7. 10,000x SEM Images of Secondary Gamma Prime Differences Due to Cooling Rate.

(Electrolytic Etchant - Methanol/Ethylene Glycol/Perchloric Acid).

\section{Microstructure}

René 65 is a gamma prime strengthened alloy that is forged and heat treated below the gamma prime solvus temperature. Figure $8 \mathrm{a}$ is a low magnification optical photograph showing a typical René 65 microstructure following forging and heat treatment. René 65 exhibits a fine grain matrix structure (typically ASTM 9 to ASTM 11) with boundaries pinned by primary gamma prime precipitates. The isolated dark appearing areas dispersed throughout the microstructure are areas of finer grains (ASTM 12 to 13) pinned by finer primary gamma prime particles, as shown at higher magnification in Figure $8 \mathrm{~b}$. Although these areas are characterized by a finer gamma prime size, the volume fraction of gamma prime is comparable to that of other areas and electron microprobe analysis does not indicate any compositional differences. These features carry-over from the billet microstructure and the volume fraction remaining is dependent on the forge processing route.

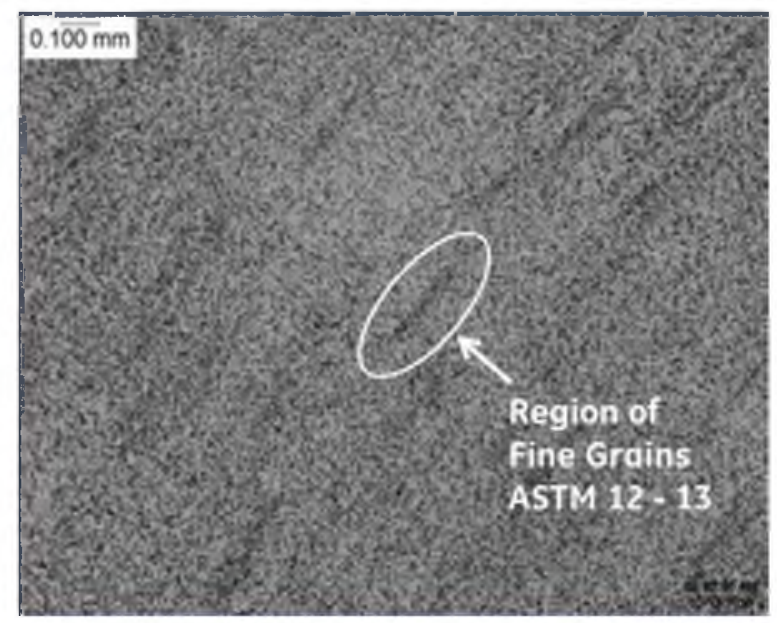

(a)

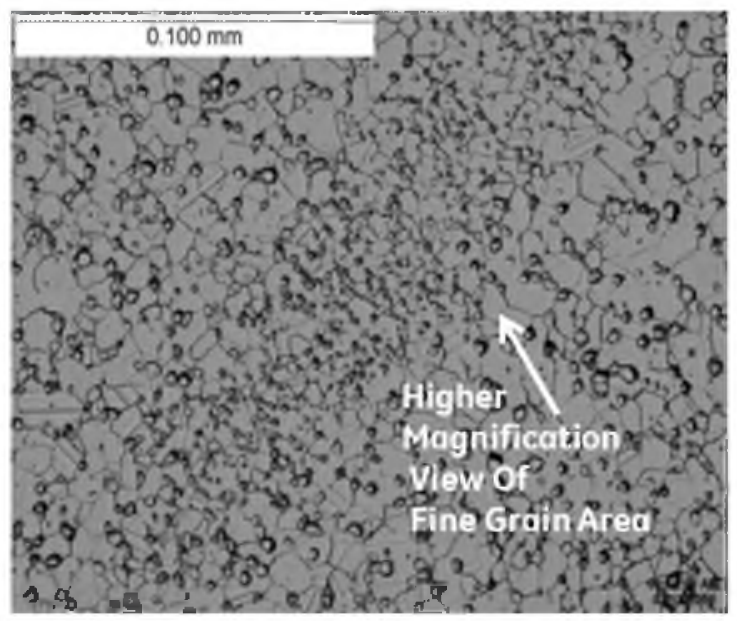

(b)

Figure 8. Typical Matrix Microstructure of René 65 (Kallings Etchant).

Unrecrystallized grains are another feature found at low volume fractions in forged and heat treated René 65. Figure 9 shows a typical unrecrystallized grain. These features also carry-over from the billet microstructure and the size and volume fraction is dependent on temperature, strain, and strain rate of the forging process. The effect of forge process variables on recrystallization of these grains is described by Minisandram et al [4]. Electron backscatter diffraction was used to obtain information on the relative orientation of the crystal structure within the region. Backscatter and band contrast images of the unrecrystallized grain are shown in Figure 10. The band contrast map shows some level of substructure in the unrecrystallized grain and the low variation in grey value suggests little orientation difference throughout the unrecrystallized region. 


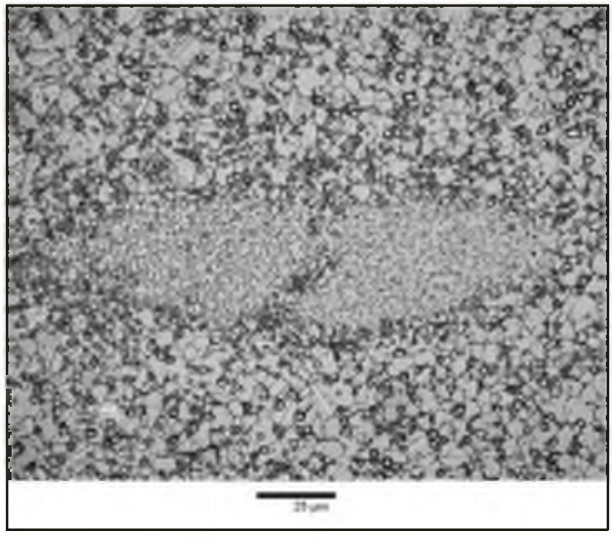

Figure 9. Typical Unrecrystallized Grain (Kallings Etchant).

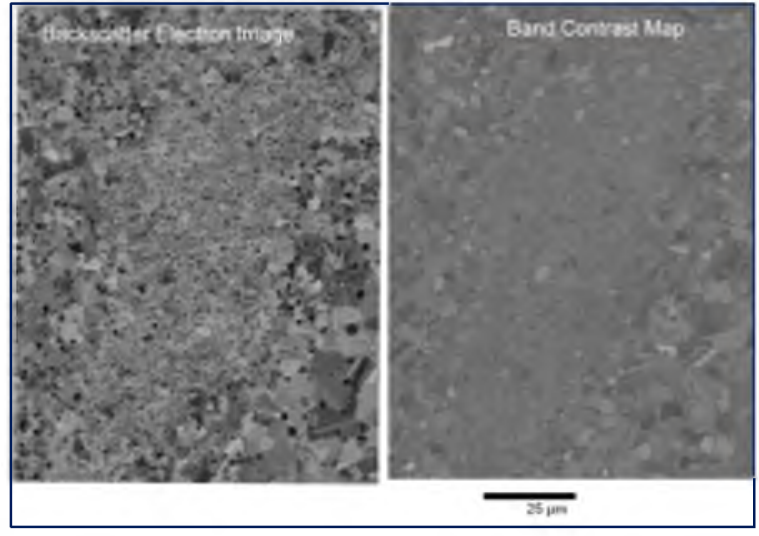

Figure 10. Backscatter/Contrast Band Images (As-Polished).

An extensive test program was conducted to determine if the unrecrystallized grains have any effect on cyclic life capability. Axial strain controled low cycle fatigue test specimens were removed from several forgings to include large unrecrystallized grains, both internal to and on the surface of the test bars, and tested at $\mathrm{A}=1.0, \mathrm{R}=0$. Post-test analysis showed the size distribution presented in Figure 11.

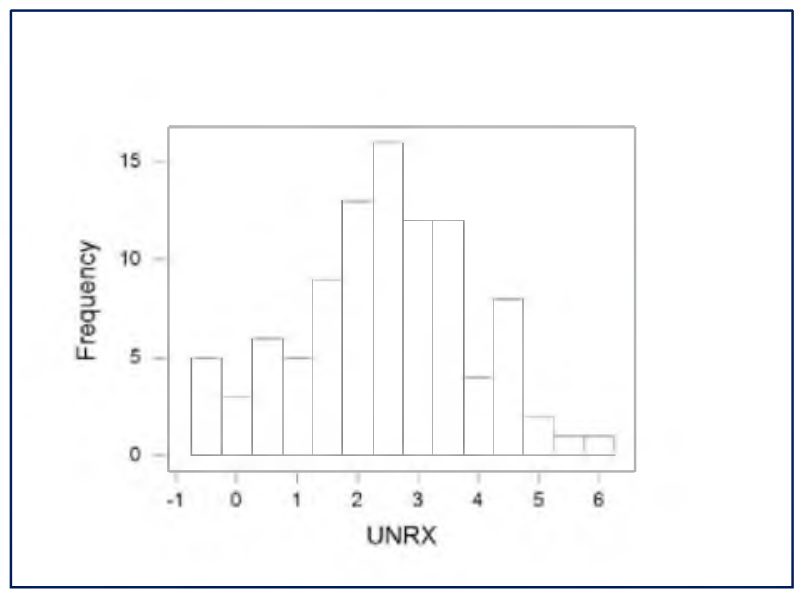

Figure 11. Distribution of Unrecrystallized Grains In ASTM Grain Sizes.

Fractographic analysis of bars tested at both $400^{\circ} \mathrm{C}$ and $649^{\circ} \mathrm{C}$ revealed that none of the failures originated at an unrecrystallized grain. The distribution of lives for material tested representing the coarsest unrecrystallized grains observed was consistent with the behavior of typical production material.

Second phase particles found in René 65 include titanium nitrides, borides (predominately Mo, $\mathrm{W}, \mathrm{Cr}$-rich), and to a lesser degree, titanium carbides. Figure 12 shows the appearance of the nitrides and borides in René 65 as well as the associated energy dispersive X-ray spectroscopy (EDS) spectra. Given the low levels of nitrogen and carbon in Rene 65, the titanium nitrides are typically found as discrete particles while discrete carbides are seldom observed. Small spherical borides (approximately 1 micron in diameter) are also observed in René 65. Similar boride 
particles have been observed in other advanced superalloys such as René 88DT [5] and Alloy 720 [6]. Due to their size, morphology, and distribution, the boride particles have not been found to influence the fatigue crack initiation behavior of René 65 .

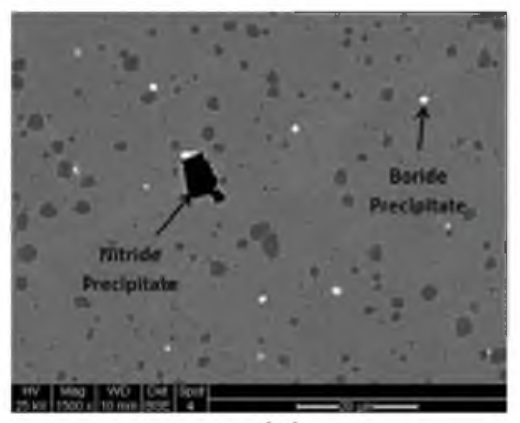

(a)

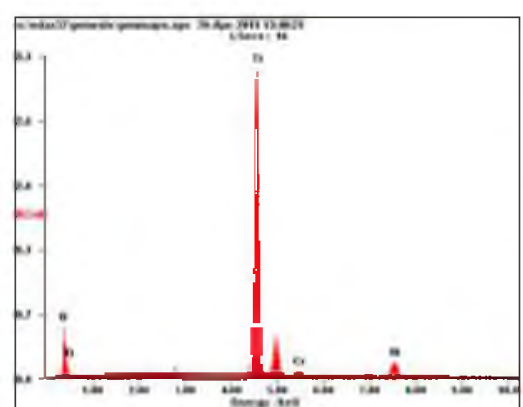

(b)

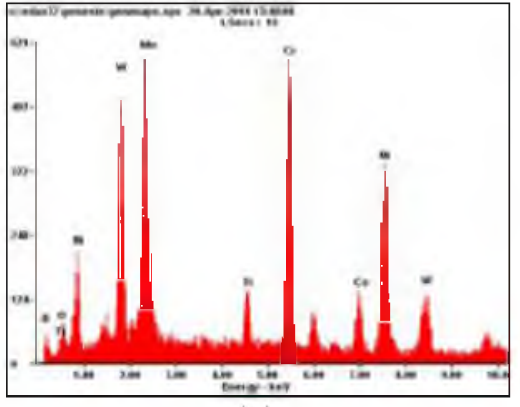

(c)

Figure 12. Backscatter Electron Image of René 65 Showing Typical Nitrides and Borides (a) as Well as Typical EDS Spectra for Nitride (b) and Boride (c) Phases.

\section{Mechanical Properties}

The mechanical properties of René 65 are optimized through the utilization of heat treat modeling to determine the required cooling path to provide the desired balance between strength, creep, and cyclic life capability. Due to the fine grain nature of the alloy, high ultimate tensile strength for burst margin is achieved providing a significant capability increase over DA718. Figure 13 shows a comparison of $0.2 \%$ yield strength and ultimate tensile strength for René 65 compared to other high temperature cast and wrought disk alloys [7].
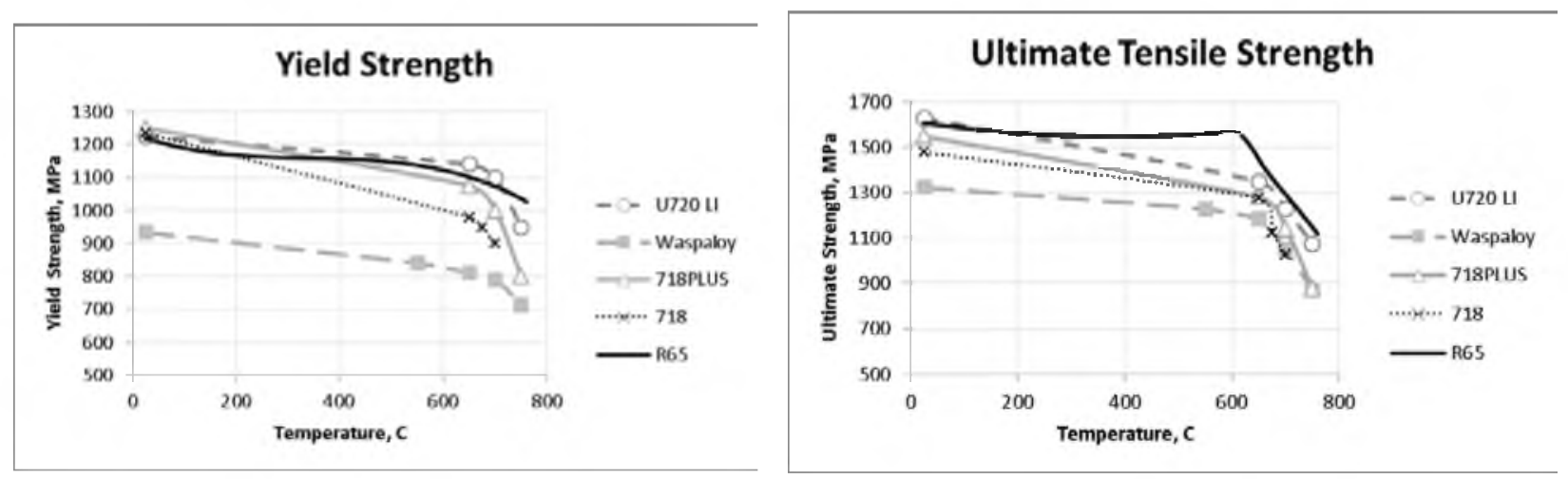

Figure 13. Comparison of René 65 Strength Capability and Other Cast and Wrought Alloys.

\section{Creep-Rupture}

Higher creep capability is one of the key criteria for design of advanced gas turbine disk components as higher operating temperatures enable increased performance. For René 65, heat treat modeling has been effective in optimizing the cooling path from the solution temperature to provide approximately a $90^{\circ} \mathrm{C}$ improvement compared to DA718. Figure 14 provides a comparison of René 65 capability to other cast and wrought disk alloys [7]. 


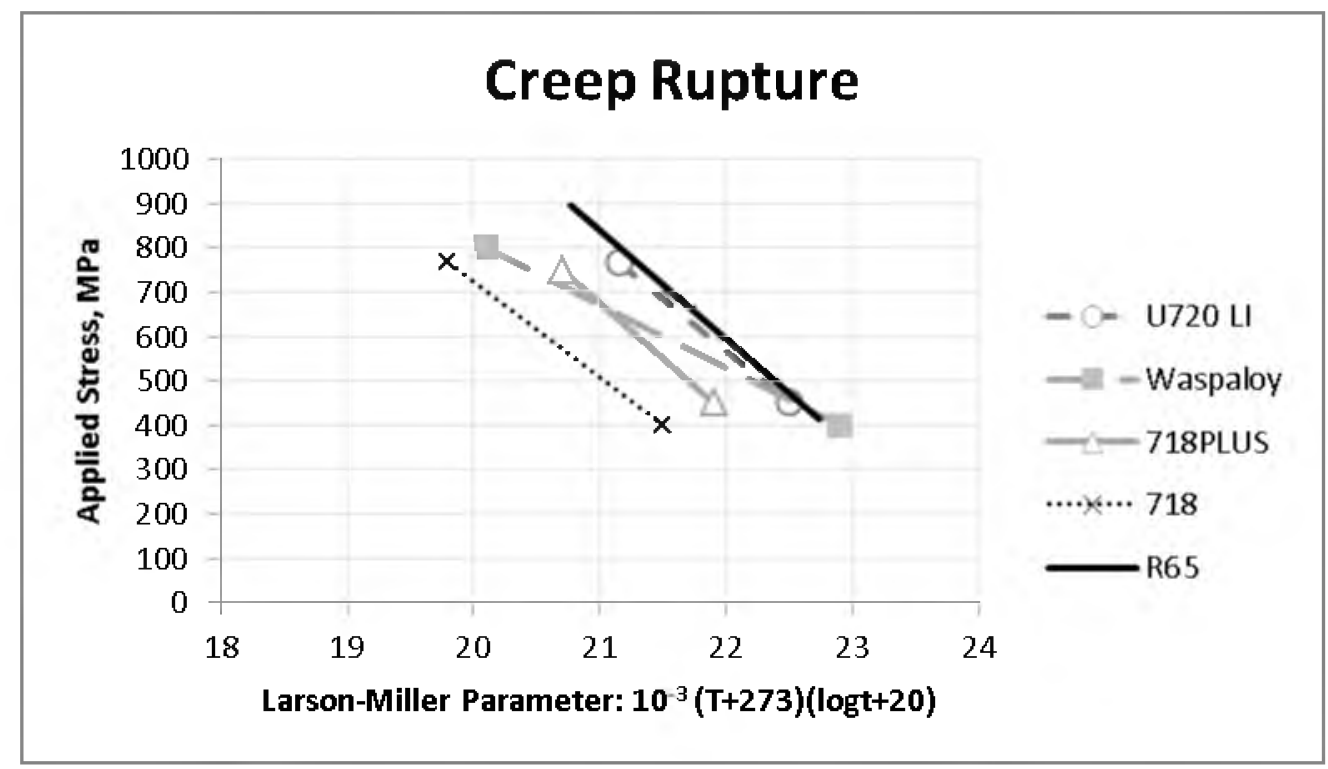

Figure 14. Creep Rupture Capability for René 65 Compared to Other Cast and Wrought Alloys.

\section{$\underline{\text { Low Cycle Fatigue }}$}

Like that for most cast and wrought alloys, René 65 low cycle fatigue behavior is a function of both grain size and material cleanliness. The prevalent initiation mode is a function of both temperature and stress level. Due to the fine grain sub-solvus microstructure and excellent microcleanliness from low interstitial processing, René 65 exhibits excellent low cycle fatigue capability as shown in Figure 15.

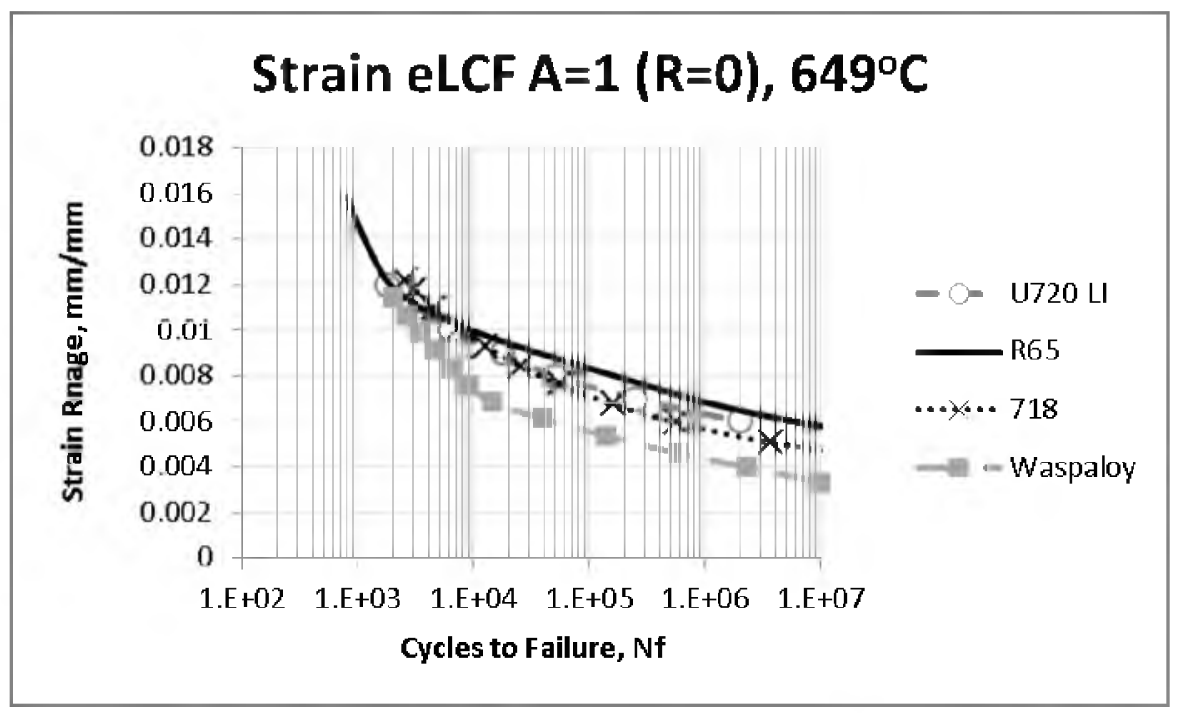

Figure 15. Low Cycle Fatigue Capability for René 65 Compared to Other Cast and Wrought Alloys. 


\section{Cyclic Crack Growth}

Following the trends of cast and wrought alloys, René 65 cyclic fatigue crack growth behavior is dominated by the grain size of the material and provides the required damage tolerance capability. Figure 16 shows that the cyclic crack growth rate of Rene 65 is similar to Alloy 718 , however, René 65 hold time crack growth capability is superior.

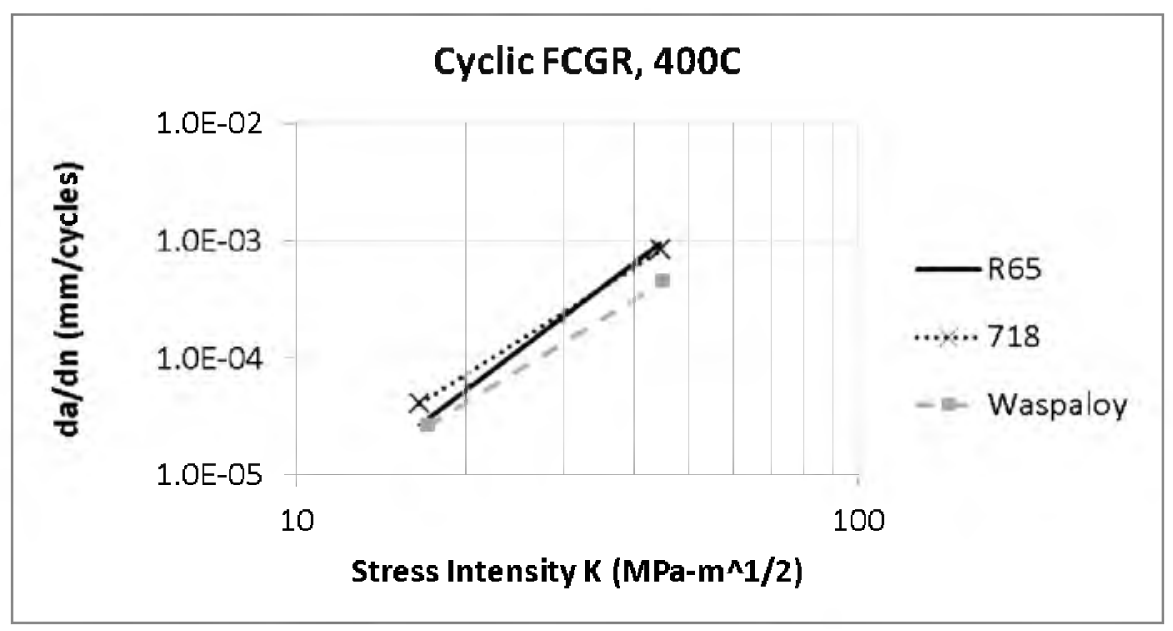

Figure 16. Cyclic Fatigue Crack Growth Capability for René 65 Compared to Other Cast and Wrought Alloys at $400^{\circ} \mathrm{C}$.

\section{Conclusions}

Joint technology development between GE and ATI Specialty Materials has resulted in the successful development and production introduction of a new advanced, gamma prime strengthened, nickel-base, cast and wrought superalloy designated René 65 . René 65 provides a cost effective alternative to expensive powder metallurgy alloys for selected turbine disk components where conventional superalloys such as Alloy 718 lack the elevated temperature capability required for new high performance engine applications.

- Chemistry modifications to R88DT powder alloy, including a nominal iron addition and low interstitial processing, were successfully engineered to facilitate cast and wrought processing and improve low cycle fatigue capability for René 65.

- Full-scale manufacture of a variety of critical rotating engine components has been demonstrated via a wide range of processes producing forgings up to $225 \mathrm{~kg}$.

- Elevated temperature properties, such as yield strength and creep, can be optimized by careful control of the cooling rate through the gamma prime precipitation range. Process modeling is beneficial in selecting the best solution heat treatment cycle to achieve the desired mechanical property requirements while minimizing residual stress for 
machinability. Proper heat treat definition results in a temperature capability for René 65 that is approximately $90^{\circ} \mathrm{C}$ higher than that of DA718.

- The sub-solvus fine grain microstructure of René 65 provides superior elevated temperature tensile strength resulting in improved burst capability compared to comparable grain size DA718 and typically coarser grain size Waspaloy, and 718Plus ${ }^{\mathrm{TM}}$.

\section{Acknowledgements}

The authors would like to acknowledge all the dedicated effort of the GE and ATI René 65 team members to bring René 65 from inception to full production in less than 5 years.

\section{References}

1. R.L. Kennedy, Allvac ${ }^{\mathrm{R}} 718 \mathrm{Plus}^{\mathrm{TM}}$, Superalloy for the Next 40 Years, Superalloys 718 , 625,706 and Various Derivatives, ed. E.A. Loria, TMS, 2005, pp. 1-14.

2. A. Devaux, B. Picque, M.F. Gervais, E. Georges, T. Poulain, P. Heritier, AD730 ${ }^{\mathrm{TM}}-$ A New Nickel-Based Superalloy for High Temperature Engine Rotative Parts, Superalloys 2012, ed. E.S. Huron et al, pp. $911-919$.

3. B.J. Bond, C.M. O'Brien, J.L. Russell, René 65 Material for Forged Turbine Components, Superalloys 718, 625,706 and Various Derivatives, ed. A. Banik, X. Liu, J. Andersson, I. Dempster, T. Gabb, J. Groh, K. Heck, R. Helmink, E. Ott, A. WusatowskaSarnek, X. Xie, TMS, 2014.

4. R.S. Minisandram, L.A. Jackman, J.L. Russell, M.L. Lasonde, J.A. Heaney, A. M. Powell, Recrystallization Response during Thermo-mechanical Processing of Alloy René 65 Billet, Superalloys 718, 625,706 and Various Derivatives, ed. A. Banik, X. Liu, J. Andersson, I. Dempster, T. Gabb, J. Groh, K. Heck, R. Helmink, E. Ott, A. WusatowskaSarnek, X. Xie, TMS, 2014.

5. S.T. Wlodek, M. Kelly, and D.A.Alden, The Structure of René 88DT, The Minerals, Metals and Materials Society, 1996. Superalloys 1996, Warrendale, PA. pp. 129-136.

6. S.E. Kim, M.P. Jackson, R.C. Reed, C. Small, A. James, N.K. Park, Quantification of the Minor Precipitates in UDIMET Alloy 720(LI) Using electrolytic extraction and X-ray diffraction, Materials Science and Engineering A, Vol. 245 [ed.], Elsevier, 1998, pp. 225-232.

7. A. Devaux, E. Georges, P. Heritier, Properties of New C\&W Superalloys for High Temperature Disk Applications, Superalloys 718, 625,706 and Various Derivatives, ed. E. Ott, J. Groh, A. Banik, I. Dempster, T. Gabb, R. Helmink, X. Liu, A. Mitchell, G. Sjoberg, and A. Wusatowska-Sarnek, TMS, 2010, pp. 223-235. 